\title{
MOTIVOS PARA DESEJAR UMA ARTE DA NÃO-COMPREENSÃO'
}

\author{
Hans-Thies Lehmann²
}

Irritação, como introdução. O impulso de tratar da não-compreensão parte das malfadadas discussões sobre os orçamentos para a cultura. Essas brigas como um todo só vêm a reforçar a impressão deprimente que inevitavelmente se obtém da sociedade alemã a partir do ano de 1990. "Tudo sairá bem barato" (Kohl); "Tudo custará muito caro" (Lafontaine) - essas afirmações representam o nível mais alto das discussões políticas sobre a unificação alemã, revelando adequadamente a cultura política nesse país. Uma sociedade que parece não necessitar de posturas político-culturais, e nem de valores, exceto os monetários, manifesta sua alma mercenária também nos recursos vergonhosamente baixos que ela destina à educação e à formação da juventude. Quando uma sociedade não dá importância a conteúdos sócio-políticos para além do valor monetário e de um correspondente moralismo desprovido de qualquer reflexão, não se deve ficar perplexo frente a esse sinal alarmante que, na verdade, mostra quão pouco a sociedade também acredita no próprio futuro. Tampouco se deve ficar surpreso com o fato de que a discussão sobre subsídios para a cultura tem sido conduzida, via de regra, a partir de uma perspectiva no fundo absurda que, no entanto, é adotada como se fosse a mais normal: precisamente que a sociedade, via Estado, deveria levantar dinheiro (ou não, ou não tanto) para que muitas pessoas possam consumir teatro. Na verdade, a questão é que a sociedade deve ou deveria ter um interesse (nem financeiro e nem de entretenimento) em que alguns (poucos) tenham a oportunidade de fazer teatro não-comercial, ou filmes complexos, ou música difícil ou pinturas não vendáveis. Somente a partir do momento em que esse tipo de consciência desaparece no abismo da ignorância, é que pode surgir a lógica perversa
${ }^{1}$ Tradução de Stephan Baumgärtel, professor da Universidade do Estado de Santa Catarina. Texto originalmente publicado sob o título "Ästhetik. Eine Kolumne. Über die Wünschbarkeit einer Kunst des Nichtverstehens", in: Merkur 48 (1994), pp. $426-431$ 
que vincula os subsídios para a arte à assim chamada "aceitabilidade". Dessa forma, chegamos ao interessante tema colateral da incompreensibilidade que tem permeado sempre as discussões sobre os orçamentos para teatros - de uma forma latente e, às vezes, até explícita.

Não-compreensão. "Certamente, ficariam amedrontados se o mundo se tornasse - como vocês exigem - real e completamente compreensível. Afinal de contas, ele mesmo, este mundo infinito, não foi formado por uma razão incompreensível e caótica?” escreveu Friedrich Schlegel (Sobre a incompreensibilidade). Foram os próprios desdobramentos mais recentes nas artes que colocaram o tema da incompreensibilidade no topo da agenda. A sua relação repulsiva com a conceitualização como tal reduz a importância da compreensão como momento da experiência estética. Se à arte compete a "expressão da incompreensibilidade" - também e não por último no teatro contemporâneo - "então desmorona a tradicional hierarquia da compreensão. No seu lugar surge a reflexão sobre o caráter enigmático da arte.” Tal comentário de Adorno na sua Ästhetische Theorie deve ser lido no contexto da sua tese de que a arte pode somente (e somente ela) articular o horror incompreensível. Mesmo se não se compartilha de tal radicalismo, permanece o fato de que as artes recusam a conceitualização que toda compreensão busca. A afirmação de Susan Sontag em Against Interpretation, de que precisaríamos de um erotismo da arte [erotics of art], em vez de uma hermenêutica, deveria ser estendida à reivindicação por uma arte do não-compreender, que somente num primeiro momento pareceria paradoxal. Essa atitude constituiria a arte e a técnica consciente da não-compreensão, tal qual existe uma arte da compreensão. A hermenêutica sempre foi considerada uma "arte", não uma técnica qualquer a ser aprendida mecanicamente. A querela sobre a idéia da “arte da compreensão" [das kunstmäßige Verstehen], nas palavras de Dilthey, é antiga, especialmente porque as instituições que se ocupam da interpretação têm um interesse muito compreensível de colocar o caráter artístico do seu ofício em segundo plano, de modo a valorizar seu aspecto técnico-estrutural. A afirmação da compreensão como valor central no relacionamento com a arte é, não por último, uma auto-proteção das instituições. A arte moderna, no entanto, tem se defendido de tal enquadramento.

Vôo panorâmico. A acusação da incompreensibilidade recai menos sobre o pequeno número de diretores quase emblemáticos para o teatro mundial e cuja ressonância internacional é incontestável, não poucas vezes depois de uma veemente recusa inicial de sua "obra" (pois é preciso dizer isso, diferente dos casos de encenadores técnicos, por mais brilhantes que sejam): Giorgio Strehler ou o gozo da commedia del mondo; Ariane Mnouchkine ou a dança simplesmente linda dos atores; Peter Brook ou a elegância do teatro pobre; mas 
também os casos mais "difíceis" como Robert Wilson ou o teatro das imagens oníricas; Jerzy Grotowski ou o teatro do corpo; Tadeusz Kantor ou o sombrio trágico-cômico. No ambiente teatral de língua alemã temos que pensar não só em Peter Zadek, aquele colagista cru (e nisso genial), mas também nos dois "irmãos" rivais, Peter Stein e Klaus Michael Grüber, no também já mítico teatro da Berliner Schaubühne de então. Trata-se de dois grandes artistas que se distinguem e separam exatamente pelo gesto da compreensão. Nos trabalhos de Stein, a tônica arrebatadora é o fato de que ele - como artista - sempre volta a levantar a enorme pretensão, ao mesmo tempo ridícula e comovente no seu impulso esclarecedor, de compreender real e seriamente as profundezas das grandes obras, desde a Oréstia de Ésquilo, passando pelos jogos enigmáticos de Shakespeare, até as caminhadas labirínticas pela alma humana de Tchekhov, e de trazer de uma forma ou outra a sua "verdade" à luz clara da compreensão através da análise cênica. A tal hibris e agonia da compreensão opõe-se, no caso de Klaus-Michael Grüber, uma experiência do enigma, um breque de compreensão. Enquanto Stein, um exímio técnico, esbanjando compreensão, com ajuda da sua tecnologia cênica que incorpora tanto o repertório dos atores, como as nuances ocultas da iluminação, desencadeia, de modo estático e imparcial, um mecanismo que, ao final, muitas vezes, deixa junto com a sensação de clareza a de uma estranha decepção, no teatro de Grüber o texto encenado se revela, no final, mais enigmático do que antes da sua encenação. No seu caso não se trata de uma tentativa de tomar o texto ao pé da letra, de entender o seu significado, mas antes de sondar o seu espaço de ressonância, onde os sinais de sentido somente consigam alcançar o seu fim através de um processo de refração, repetição e multiplicação, de modo a tornar-se então incompreensíveis. No primeiro, encontramos a iluminação esclarecedora. No segundo, um mundo fantasmático de sombras e enigmas. A lente de Grüber só capta uma parte da radiação textual, mas a focaliza e assim a transforma em chama. Não para celebrar um sacrificium intellectus, mas para circundar com linguagens o limiar do indizível, como o fez Freud; para poder apontar com palavras para o que não tem palavras, como fez a poesia moderna de Mallarmé até Ponge.

$O$ efeito da não-compreensão. A procura pela compreensão visa a um fechamento. $\mathrm{O}$ mesmo gesto que abre e emoldura o que foi aberto, fecha o que acabou de ser aberto de forma que fique inteiramente apreensível. Se considerarmos o teatro como o paradigma da experiência estética (o que se justifica tanto pela tendência à teatralização das artes, quanto pelas categorias estéticas do "acontecimento", do "performático", do instantâneo e do cênico que desempenham um papel central na teoria contemporânea), então fica óbvia aqui a relatividade da compreensão e a prioridade da experiência sobre a compreensão. A arte daquilo que Brecht chama a Zuschaukunst [a arte 
tanto de ver quanto de assistir] não é a arte de compreender algo da melhor forma possível; o tempo do espectador durante uma montagem é mais do que a seqüência de seus atos de compreensão. Ele experimenta uma condensação específica do tempo e da percepção sinestésica, além de uma sobreposição dos espaços empírico-biográfico e estético. É mais comum perceber nesse processo os vários graus e estágios da compreensão, do que perceber que necessariamente hão de existir graus e estágios correspondentes de uma nãocompreensão [Nicht-Verstehen]. Vamos chamar isso o $N V$-Effekt, efeito de nãocompreensão, pois já possuímos um $V$-Effekt, o Verfremdungseffekt de Brecht. O $N V$-Effekt já é causado pela percepção simultânea de códigos diferentes: signos teatrais são miméticos tanto pelo mecanismo da semelhança (o ícone), por sua codificação convencional (o símbolo) bem como por seu caráter designativo (o índice), e os processos simultâneos de percepção produzem necessariamente interferências. Soma-se a isso ainda a velocidade da seqüência dos signos e o fato de que eles não podem ser repetidos. Não se pode folhear para trás, pausar, repetir, mas tem de seguir a "sucção" do tempo cênico. Essa tendência para as interferências, que existe de uma forma latente no teatro, bem como em todas as artes efêmeras, naturalmente aumenta quando a história do teatro avançado é a da sua incompreensibilidade - como é o caso nesse século [XX]. As provocações da vanguarda histórica na virada do século XIX para o XX divergem nas intenções, mas compartilham uma renúncia do ideal da compreensibilidade: sustam a compreensão como negação de uma civilização julgada por elas como pseudo-racional; no futurismo, a incompreensibilidade serve como liberação de uma agressão revolucionária; no surrealismo, o desrespeito da ratio e da lógica visa obter acesso a mundos inconscientes de fantasia e experiência. E até a teoria do "valor material" de Brecht, iluminista explícito, deve ser lida como uma teoria de uma não-compreensão intencional e artística. Para o mainstream da filologia brechtiana, essa teoria faz parte da sucata na obra de Brecht, desprezado como um radicalismo indefensável. No caso do próprio Brecht, no entanto, ela significa recuperar material "cego" que, para o autor ou diretor contemporâneo, pode manter-se vivo, produtivo e útil exatamente por que a recepção do material é limitada ao mínimo possível através da consideração da sua lógica imanente (ainda a ser compreendida).

Procedimento. O impulso de criação no trabalho teatral contemporâneo origina-se essencialmente de uma recusa da compreensão; parte da produção de processos cênicos que geram o bloqueio da compreensão do seu sentido. Alguns exemplos: a semiótica vazia do belga Jan Fabre, em cujo trabalho se manifesta uma implacável expulsão do espírito pela estrutura; geometrização e número desautorizam o conceito e comunicam a inutilidade da compreensão e da empatia, para alcançar uma percepção nítida, puramente estrutural e muitas vezes torturante, que se funde com a comunicação de medo e dor. Ou pensemos no excesso quantitativo de signos teatrais que não podem ser 
sintetizados através de atos de compreensão, pois obrigam a um modo seletivo e fragmentário de percepção, e dessa forma ao reconhecimento que uma compreensão do processo como um todo fica fora do âmbito do possível (isso se aplica à dança de William Forsythe). Ou consideremos a presença hiperbólica do corpo, da sua materialidade e sexualidade, compostas por respiração, suor, dor e esforço; expressões de atração e repulsa - impulsionados pela mera physis - que se sobrepõem imperiosamente ao processo de compreensão; disjunção e incoerência dos procedimentos cênicos que não demonstram nenhuma relação entre si. Fica por conta da subjetividade dos espectadores produzir uma síntese racional, e ela se mantém virtual (exemplo disso é o trabalho de Bob Wilson). Ou a dissolução das molduras/límites que separam o mundo teatral fictício e real no teatro tradicional: Apresentação e ensaio, a ficção na platéia e o mundo exterior se sobrepõem (entre outros meios, através do uso de vídeo); no caso da Wooster Group, por exemplo, falas diretas ao público deixam este em dúvida se, num determinado momento, um ator está incorporando um papel ou se está falando como pessoa empírica. Pela decomposição do frame of reference, do qual todo processo de compreensão depende, bloqueia-se a compreensão. Embora tais grupos ou pessoas sejam conhecidos somente por um público especializado, eles exercem, de forma indireta, uma influência profunda e abrangente, pois influenciam os jovens diretores e produtores teatrais da vanguarda atual. Acrescentemos ainda: Heiner Müller e seu teatro textual do horror; o formalismo de Tadashi Suzuki, inspirado tanto pela antiga tradição japonesa quanto por impulsos pós-modernos; o arcaico artístico de Andrei Serban; o teatro-dança de Pina Bausch; a postmodern dance desde Merce Cunningham; o grupo italiano Magazzini; e no âmbito nacional alemão, as posições extremas da estética de encenação dos diretores da RDA, como Einar Schleef.

A tendência é clara - não só no teatro contemporâneo mas também nos desdobramentos recentes da música erudita ou das Artes Plásticas: a recepção tropeça, e isso de uma forma intencional. Mas como responde a teoria a esse fenômeno? Através de concepções, cada vez mais elaboradas, para formar sínteses, estruturas lógicas e chegar a uma compreensão; concepções que não focalizam tal tropeço, mas se esforçam ao máximo para colar os cacos e manter o equilíbrio. A mudança de perspectiva necessária, que seria apropriada aos fenômenos, começa com a problematização da perspectiva em si. A idéia da compreensão implica um ponto de vista a partir do qual e em direção ao qual se organiza um campo que, não obstante sua incompletude empírica, é, por princípio, um campo total. O que acontece com esse ponto de vista da compreensão quando o olhar totalizador falha, se recusa? Sem centro não há um curso que poderia ser fixado. A compreensão se torna parcial, se contradiz e se interrompe, ela falha e retorna, vibra - e dessa maneira, torna-se experiência. Experimentar [erfahren] ou compreender [verstehen]: a tensão se expressa nas 


\section{Urdimento}

${ }^{2} 0$ autor brinca com os termos alemães Erfahrung (experiência) e Verstehen (compreender), cujas raízes fahren e stehen significam, respectivamente, "ir, movimentar-se" e "estar de pé e imóvel". [NT]

\footnotetext{
${ }^{31}$ Queremos - a tal ponto este fogo nos ferve 0 cérebro mergulhar [...] no fundo do desconhecido para achar algo de novo!"
}

próprias palavras 2 . O conceito só conhece uma única hierarquia: experimentase algo para entendê-lo. No âmbito da arte, isso não vale: a compreensão não tem como objetivo o repouso, mas a cesura que propulsiona os sentidos e os pensamentos, colocando-os nos trilhos da experiência que prefere não chegar ao destino final do conhecido e do compreendido. Os viajantes de Baudelaire: "Nous voulons, tant ce feu nous brûle le cerveau, / Plonger [...] au fond de l'Inconnu pour trouver du nouveau!" (Le Voyage) ${ }^{3}$. Na vida real pragmática, a não compreensão é uma sombra sobre a compreensão que por vezes incomoda, mas que na maioria dos casos se aceita com indiferença. No entanto, para quem vivencia uma encenação teatral o compreender se torna, ao contrário, uma sombra - necessária - da não-compreensão que por sua vez é primordial. É como no caso do chiste que, em última instância, não se conta ou se ouve por amor ao seu ponto alto, mas pelo riso em que explode todo e qualquer sentido. No teatro, precisa-se de um pouco de compreensão, para se chegar à não-compreensão.

$A$ arte de não-compreender. Uma condição fundamental da experiência estética que se diferencia de uma apreensão conceitualizadora, seria - no sentido do destronamento da configuração em torno de uma perspectiva central - a recusa da figuração básica da compreensão, isto é, a distinção do essencial e do não-essencial, do central e do secundário. Da mesma forma que a pintura moderna deixou de opor o "centro" conceitual e pictórico à "moldura", o primeiro ao segundo plano, o interesse numa práxis do efeito da nãocompreensão (efeito NV do Nicht-Verstehen) exige que não se desvie a atenção e o olhar da margem, do detalhe, do colateral. Uma poética da compreensão é substituída por uma poética da atenção que armazena o estímulo e o mantém na pré-consciência; que lhe possibilita uma inscrição efêmera no aparelho perceptivo sem permitir que ele se dissipe num ato de compreensão: um rastro de memória ao invés de consciência, a compreensão fica adiada.

A procura por técnica e treinamento, isto é, pelo aspecto do ofício na arte da não-compreensão, em analogia com as regras hermenêuticas, leva à regra básica de Freud da "atenção igualmente flutuante" (gleichschwebende Aufmerksamkeit), com a qual o analista deveria seguir o discurso do paciente, uma analogia técnica à livre associação deste. A suspensão da compreensão conceitual, a disponibilidade flutuante de prestar atenção, deverá possibilitar uma forma mimético-sonora de escuta dos significantes, pois o ato de compreender, que cai na armadilha montada pelas estruturas discursivas, desentenderá tudo, exatamente porque a estruturação do discurso segundo centro e moldura, primeiro e segundo plano, aspecto principal e colateral, já é conseqüência de uma censura. Portanto, a estruturação nunca é representação sem ser, ao mesmo tempo, uma desfiguração. O que surge como significância deverá ser captado como rastro que nunca se apresenta a partir de um único 
ponto de vista como presença e tableau ordenado de forma clássica, mas que só é passível de ser vivenciado como possibilidade múltipla de leitura. É preciso relacionar a fala a outras conexões, em vez de compreendê-la, até que ela se aproxime às conexões perdidas no sujeito. Tal tipo de compreensão produz a não-compreensão, efeitos da não-compreensão, no sentido de que ela atravessa todas as cesuras da "interpretação" e assim se dissolve em seus rastros, modula o discurso, sem tornar-se um fim em si mesmo. Isso é possibilitado por uma flutuação da atenção (como indicam as traduções do termo técnico de Freud: atenção flutuante, attention flottante, attenzione fluttuante), que não se deixa dirigir a partir do centro, mas que se abre para as margens, notas de rodapé, e os efeitos colaterais e pouco perceptíveis do discurso, nos quais a fala se expressa: modelo de uma arte/técnica da não-compreensão.

Desenvolto. Quem visa não uma interpretação iluminadora, mas uma práxis que evite o gesto da interpretação - humilde somente na aparência -, precisará pensar paradoxalmente a não-compreensão ao mesmo tempo como uma máquina híbrida e reacoplada, no sentido de Deleuze e Guattari, que não quer desmentir o seu caráter performativo, afirmativo e inventivo. A encenação é disseminação [Auslegung] no sentido literal da palavra: outrora o desenrolar dos pergaminhos, aqui o desdobramento espacial do tex to ${ }^{4}$. A encenação, por sua vez, será desdobrada/desenrolada pelos espectadores. Para ambos, a crítica à hegemonia da compreensão não pode significar o fim da "interpretação" no sentido de Nietzsche - como interpretação "forte", cheia de riscos, que cria algo novo. Especialmente a interpretação contemporânea chamada "infiel" se mostra apropriada aos textos clássicos, não a interpretação supostamente fiel às obras. Pelo contrário, o mal-entendido produtivo se revela não como uma modalidade da tradição, mas como a sua essência. Isso seria importante acrescentar às idéias abrangentes de Jochen Hörich em seu livro O furor da interpretação. O conceito da interpretação de Nietzsche não pode ser lido como um "diagnóstico" do furor hermenêutico em direção à interpretação. Em vez disso, Nietzsche quer afirmar o direito à interpretação "estupradora", transfiguradora, até traidora ao seu objeto, que, no entanto, afirma algo novo e não se submete ao ditado da compreensão. (Aliás, enquanto furor, a compreensão é - graças a Deus - justamente cega, revela-se como pulsão e vontade de poder.)

Pará. Produzir o $N V$-Effekt não significa uma negação abstrata do ato de compreender, mas uma mudança na hierarquia. Trata-se de um adiamento, uma suspensão, um deslocamento e uma auto-desmontagem. O que importa é uma compreensão ao mesmo tempo desenvolta ${ }^{5}$ e suplementar ${ }^{6}$. Ambos as modalidades deveriam ser refletidas, por um lado, à luz da "Gaia Sciência" [de Nietzsche], por outro, à luz do conceito Freudiano de posterioridade. A práxis

${ }^{4} 0$ autor brinca com a palavra "Auslegung" que significa literalmente "espalhamento, exposição em área plana" e figurativamente "interpretação ou exegese de um texto". [NT]

5"Ausgelassen" em alemão; adjetivo que abre associações como "alegre, desinibido e despreocupado". [NT]

${ }^{6 " N a c h g e t r a g e n " ~ e m ~}$ alemão;particípio verbal que implica "levado ou acrescentado posteriormente" 0 que remete à idéia de Derrida da função do suplemento como elemento que se acrescenta à estrutura sem completá-la. [NT]

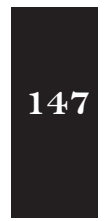


da não-compreensão é uma forma de deixar acontecer, de possibilitar uma experiência (para isso, precisa-se de certa prática); semelhante ao esquecer ativo de Nietzsche, é uma atividade e não mera vis inertiae. Seria mais uma arqueologia do que compreensão histórica. Seria uma experiência de correspondências que não indicaria mais uma simples variação da percepção artística, mas o seu princípio. Através de todas as camadas e nuances da compreensão, a nãocompreensão se deixa tocar por uma súbita correspondência, como talvez tivesse acontecido na primeira percepção da voz materna na qual não se compreendeu o sentido, mas vivenciou-se o estar conectado. Finalmente, faz parte da práxis do $N V$-Effekt um modo de representação da auto-desmontagem; de uma ironia que conhece a si mesma e se auto-ironiza, no sentido de Paul de Man. Sempre há algo que frustra a afirmação do cálculo conceitual. Isso poderá não mais produzir uma doxa, mas uma paradoxa: um gesto de inversão, que se acopla como um parasita (um companheiro de mesa que come ao lado de ou junto com alguém) aos atos de compreensão - e os consome. Produz a paráfrase e talvez até, horribile dictu, uma para-arte na qual a opinião se mantém parábola. Eis uma disseminação do termo grego pará: ao lado, junto, passando por, da parte de, do lado, para, para fora, para o lado, na distância de, com uma diferença de...

Apreender a não-compreensão. Pode-se objetar que tudo isso possa ser aplicado com certa justificativa aos interessantes fenômenos (e certamente aos exemplos extremos) da modernidade, mas não à tradição clássica. Por isso, finalizando, uma referência aos primórdios do teatro. O teatro, principalmente o trágico, certamente visava sempre uma aprendizagem. Desde Ésquilo e seu lema famoso pathei mathos - aprender através do sofrimento - e passando por Aristóteles e Lessing até Brecht. Mas o que é apreendido? Qual é o objeto do reconhecimento que se oferece ao herói através do seu sofrimento? Dito da forma mais direta possível: o que se compreende aqui, e principalmente aqui, é a não-compreensão. O teatro grego continua paradigmático precisamente neste aspecto, que no sofrimento se reconhece a ilusão da compreensão; a alienante estranheza na ação arbitrária dos deuses que é o nome para o inconcebível. A esse reconhecimento corresponde não a compreensão, mas o gesto: a lamentação, a oração, o luto, a aflição, o choro, o susto, a compaixão. Anagnorisis, o reconhecimento, é o momento trágico em que um acontecimento chocante e enigmático adentra a percepção; o momento que suspende toda a continuidade do ato de compreender; é uma fissura na imagem e uma cesura, não importando se ela produz uma virada inicialmente favorável (Elektra) ou destruidora (Édipo). Desde a antiguidade, o teatro se afirma como o lugar onde se apreende a perceber a não-compreensão. Muitas vezes questionouse os motivos pelos quais Aristóteles realçou os dois afetos phobos e eleos, o horror arrepiante e a aflição compassiva. No entanto, se concebemos o teatro 
como uma aprendizagem da não-compreensão, simultaneamente se desvenda esta leitura da teoria da catarse: $\mathrm{O}$ horror, phobos, é a percepção arrepiante e o choque da experiência da não-compreensão dos poderes chamados divinos. No triângulo trágico herói-deuses-espectadores, o phobos se refere ao eixo herói e deuses. Eleos, compaixão, se refere ao eixo herói e espectadores. O teatro lhes oferece a visão daqueles que experimentam o horror; eleos surge da identificação com o sujeito sofredor. Dessa forma, os dois afetos phobos e eleos realmente são aqueles que cobrem as dimensões do teatro trágico. Não é só a partir da pós-modernidade que o teatro é um lugar de uma arte onde se aprende sobre a não-compreensão. Apreende-se precisamente assim que somente uma forma de percepção se mostra à altura dessa experiência que não evite o esforço de exercitar-se na arte da não-compreensão. Talvez, "os cegos" - partindo de Agamêmnon, Édipo, e Heráclito, e passando por Lear e Hamlet até a Mãe Coragem de Brecht e os personagens de Beckett - sejam arquétipos do teatro, porque o teatro sempre foi o lugar em que se experimentava o fracasso da compreensão. 